\title{
A COESÃO TEXTUAL EM TEXTOS NARRATIVOS: uma análise em textos nas duas modalidades da Lingua Portuguesa
}

\author{
Claudiele da Silva Pascoal \\ (UFSM) \\ https://orcid.org/0000-0002-6265-9981 \\ Gil Roberto Costa Negreiros \\ (UFSM) \\ https://orcid.org/0000-0002-9161-7967
}

\section{RESUMO}

Este artigo pretende apresentar uma análise da Coesão Referencial em textos produzidos em oficinas de produção textual na Escola Básica. A importância desse tipo de estudo está na oportunidade de apontar os recursos linguísticos utilizados pelos alunos para promover a referenciação e a relevância de, em sala de aula, os professores explorarem as mais diversas estratégias linguísticas promotoras da referenciação. A fundamentação teórica que embasou o trabalho é a Linguística do Texto cujos estudos utilizados encontram-se nas obras de Koch e Travaglia (2003), Antunes (2005), Fávero (2004) e Koch $(2017 ;$ 2018). Este artigo de cunho descritivo-analítico de base quanti-qualitativa analisa parte do corpus coletado em minha pesquisa de mestrado que ocorreu no segundo semestre do ano de 2018. A metodologia utilizada na pesquisa foi a pesquisa-ação, proposta por Thiollent (2011) e Tripp (2005), pois essa metodologia permite ao professor observar a realidade dos sujeitos envolvidos na situação, planejar estratégias que auxiliem na resolução de problemas e dificuldades, implementar as estratégias, monitorar os resultados esperados e alcançados e, se necessário, recomeçar nesse ciclo até que obtenha os resultados desejados. A análise de um texto escrito e um texto oral produzidos por um aluno do sexto ano do Ensino Fundamental apresentará as formas de referenciação utilizadas nos textos a fim de caracterizar os textos produzidos nas duas modalidades da língua.

Palavras-chave: Coesão referencial; Texto escrito; Texto oral. 


\section{TEXTUAL COHESION IN NARRATIVE TEXTS: an analysis of texts in both Portuguese language mo- dalities}

\section{ABSTRACT}

This article aims to present an analysis of Referential Cohesion in texts produced in textual production workshops at the Basic School. The importance of this type of study is the opportunity to point out the linguistic resources used by students to promote referencing and the relevance of teachers exploring the most diverse language strategies that promote referral in the classroom. The theoretical foundation behind the work is Text Linguistics, whose studies are found in the works of Koch and Travaglia (2003), Antunes (2005), Fávero (2004) and Koch $(2017 ; 2018)$. This quantitative and qualitative descriptive-analytical paper analyzes part of the corpus collected in my master's research that took place in the second semester of 2018. The methodology used in the research was the action research, proposed by Thiollent (2011) and Tripp (2005), because this methodology allows the teacher to observe the reality of the subjects involved in the situation, to plan strategies that help in solving problems and difficulties, to implement the strategies, to monitor the expected and achieved results and, if necessary, to restart this cycle until desired results are achieved. The analysis of a written text and an oral text produced by a sixth grade elementary school student will present the referencing forms used in the texts in order to characterize the texts produced in both modalities of the language.

KEYWORDS: Referential Cohesion; Written text; Oral text. 


\section{Considerações iniciais}

Os Parâmetros Curriculares Nacionais (BRASIL, 1997) orientam que, nas aulas de Língua Portuguesa, é imprescindível o trabalho com produção textual nas duas modalidades da língua de modo que os alunos desenvolvam as habilidades de se expressar na sociedade. Além disso, os PCNs apontam para a importância do trabalho com o texto não como produto acabado, mas como processo, já que texto é um todo, não apenas um amontoado de palavras, frases ou parágrafos, que se constitui de termos e partes com relações sintático-semânticas.

Para o sexto ano do Ensino Fundamental, os PCNs sugerem a exploração de atividades de produção de textos narrativos. Por isso, esse tipo textual foi explorado na implementação de oficinas semanais, nas aulas de Língua Portuguesa, em minha pesquisa de mestrado. Assim, este artigo está relacionado com minha pesquisa e com a produção de minha dissertação, já que analisamos na dissertação a coesão referencial em textos escritos e orais produzidos em sala de aula na Escola Básica.

O estudo realizado neste artigo, que apresenta um recorte da minha dissertação de mestrado, aponta os recursos linguísticos utilizados pelos alunos para promover a referenciação nos textos. Isso é relevante porque assinala aos professores que eles podem explorar diversas estratégias linguísticas promotoras da referenciação nos textos dos alunos nas aulas de produção textual na disciplina de Língua Portuguesa.

Os objetivos deste artigo são: averiguar as ocorrências de mecanismos linguísticos responsáveis pela coesão referencial em dois textos, um escrito e um oral, produzidos em sala de aula; e, verificar a ocorrência de traços comuns nas duas modalidades de textos com relação à coesão referencial.

Será analisado em um texto escrito e um texto oral de um aluno do sexto ano do Ensino Fundamental a coesão textual, mais especificamente, a coesão referencial de acordo com os estudos de Koch (2018). Estudos semelhantes a esse que abordem a coesão textual também em textos orais não foram encontrados em pesquisa no Portal da CAPES. Encontramos apenas: "A coesão Textual em narrativas de alunos do $7^{\circ}$ ano do Ensino Fundamental", de Maria Helena Corrêa da Silva Matei, orientada pela $\operatorname{prof}^{\mathrm{a}}$. Dra . Leonor Lopes Fávero, na Pontifícia Universidade Católica de São Paulo (PUC-SP), no ano de 2012; e "A referenciação em produções escritas de estudantes do Ensino Fundamental: desafios e perspectivas", 
de Sílvia Maria da Silva, orientada pela prof ${ }^{a}$. Dr ${ }^{\mathrm{a}}$. Lúcia de Fátima Santos, da Universidade Federal de Alagoas, em 2013. Portanto, é relevante a produção de trabalhos que abordem o estudo da coesão textual em textos orais.

Este artigo constitui-se das seguintes seções, além das considerações iniciais: fundamentação teórica, que abordará a Linguística do Texto e a Coesão Textual, a metodologia, a análise do corpus, e, por fim, as considerações finais. Após essas seções, seguem as referências bibliográficas.

\section{Fundamentação teórica}

\section{A linguística do Texto}

A Linguística Textual é o ramo da Linguística cujo objeto de estudo é o texto. Durante o percurso dessa vertente linguística, várias foram as concepções de texto utilizadas até que se chegasse a atual. Entre as etapas de evolução há diferenças bastante significativas.

A Linguística Textual surgiu na segunda metade da década de 1960. Nessa época, o foco recaía na análise transfrástica e na construção da gramática do texto. Assim, o texto era considerado uma "sucessão de unidades linguísticas constituída mediante uma concatenação pronominal ininterrupta" (KOCH, 2017, p. 19) e os estudos voltavam-se para o encadeamento dos enunciados, para a articulação tema-rema e estudo de recursos de coesão textual.

Destacava-se apenas o estudo da coesão e da coerência, que eram vistos como qualidades do texto. Com a preocupação com a construção da gramática do texto, foi considerada a existência de uma competência textual, já que texto é diferente de aglomerado de enunciados incoerentes. Surge a ideia de que o texto é "uma estrutura determinativa onde tudo está necessariamente interligado" (KOCH, 2017, p. 22).

Estudiosos passaram da abordagem sintático-semântica para uma visão em que o texto é a unidade básica que permite a comunicação e a interação humana. Nessa perspectiva pragmática, surgem as teorias de base comunicativa e os estudos passam a ter como base as Teorias dos Atos de Fala com pressupostos da teoria da Atividade Verbal. Assim, o texto passa a interessar em sua função, em funcionamento nos processos comunicativos da sociedade. Com isso, os textos deixam de ser produtos acabados para serem textos que realizam as intenções comunicativas e sociais do falante. 
Na década de 1980, na chamada abordagem cognitivista, o texto passou a ser visto como resultado de processos mentais. O conhecimento linguístico compreende os conhecimentos gramatical e lexical e o conhecimento de mundo (enciclopédico), o conhecimento sociointeracional, o comunicacional e o metacomunicativo passaram a ser considerados. Ampliou-se o conceito de coerência, pois ela se constrói ao longo da interação em função de outros fatores envolvendo o texto e seus usuários, fatores esses de ordem linguística, cognitiva, sociocultural e interacional. Nesse período foram incorporados aos estudos outros fatores de textualidade: informatividade, situacionalidade, intertextualidade, intencionalidade, aceitabilidade, contextualização, focalização, consistência e relevância.

Na década seguinte, 1990, os processos de organização dos textos ganham importância. Somados a eles havia questões de ordem sociocognitiva, envolvendo outros temas como referenciação, inferenciação, acesso ao conhecimento prévio, etc. Muitos outros tópicos vieram a ser tratados como, principalmente, o estudo do texto falado.

$\mathrm{Na}$ abordagem sociocognitivo-interacionista, a atividade linguística é baseada na interação e no compartilhamento de conhecimentos e atenção entre os indivíduos em atividade conjunta. Assim, as ações verbais são conjuntas porque usar a linguagem é engajar-se, de alguma forma, em uma ação que é o próprio lugar em que ação ocorre em contextos sociais, com finalidades sociais e em que os indivíduos desempenham papéis também sociais. Tudo acontece em um contexto social e histórico (KOCH, 2017, p. 43).

A linguagem cumpre um papel mediador na interação e o contexto constitui a própria interação e os sujeitos envolvidos. Na concepção interacional da língua (também chamada de dialógica), os sujeitos são os atores sociais, o texto é o lugar da interação e os interlocutores são sujeitos ativos que se constroem e são construídos ao longo do processo interativo (KOCH, 2017, p. 44). A produção de linguagem constitui a atividade interativa que é complexa e responsável por produzir os sentidos.

Baseada nos estudos mais recentes da Linguística do texto e nos critérios de textualidade apontados por Beaugrande e Dressler (1981), trabalhamos na pesquisa de mestrado com o critério da coesão textual, mais especificamente, a coesão referencial. Nesse artigo, também atentamos para a coesão referencial, analisada em um recorte do corpus coletado na pesquisa de mestrado. Passaremos, a seguir, para as considerações acerca da Coesão Textual. 


\section{A coesão textual}

O estudo da coesão textual vem sendo desenvolvido pela Linguística do Texto, um dos ramos da Linguística Moderna. Tomaremos por base, principalmente, os estudos sobre coesão textual de Koch (2018). Porém, também traremos alguns embasamentos de outros estudiosos do texto que tratam com especificidade o fenômeno da coesão textual como Koch e Travaglia (2003), Antunes (2005), Fávero (2004).

O estudo da coesão textual só é possível por meio da materialidade do texto. O texto, enquanto objeto de investigação da Linguística Textual, não é uma reunião de palavras ou de sentenças isoladas, mas sim uma unidade básica de manifestação da linguagem. É por meio dos textos que o homem se comunica e há fenômenos que só podem ser explicados no interior do texto.

Conforme Koch e Travaglia (2003), de forma diferente da coerência, a coesão é revelada de maneira explícita no texto por meio das marcas linguísticas, pelos índices formais na estrutura da sequência linguística e superficial do texto. Por isso, é de caráter linear, por se manifestar na organização sequencial do texto. A coesão é "a relação semântica entre um elemento do texto e outro elemento que é crucial para sua interpretação" (KOCH e TRAVAGLIA, 2003, p. 13), é a ligação entre os elementos presentes na superfície do texto de maneira que ao se relacionarem propiciam o desenvolvimento proposicional do texto, é "a relação semântica entre dois elementos do texto, de modo que um deles tem de ser interpretado por referência ao outro, pressupondo-o" (KOCH e TRAVAGLIA, 2003, p. 15).

A coesão e a coerência estão fortemente relacionadas no processo de produção e compreensão do texto (KOCH e TRAVAGLIA, 2003, p. 23). No entanto, é importante destacar que a coesão contribui para estabelecer a coerência, mas não garante sua obtenção. Ainda que os elementos coesivos auxiliem no estabelecimento da coerência, eles não são suficientes dependendo de alguns elementos externos ao texto, ou seja, "pode haver sequências linguísticas coesas, mas para as quais o leitor não consegue estabelecer ou dificilmente estabelece um sentido que the dê coerência" (KOCH e TRAVAGLIA, 2003, p. 24). Assim, a coesão auxilia na percepção da coerência na compreensão dos textos, porque é resultado da coerência no processo de produção desses mesmos textos.

A coesão textual não é condição necessária para que um texto seja considerado texto, porém ela confere a ele legibilidade e explicita as re- 
lações estabelecidas entre os elementos linguísticos presentes na tessitura do texto por meio da presença de mecanismos capazes de relacionar as partes do texto.

Assim, há elementos textuais com a função de remeter a referentes já citados no texto (fenômeno chamado de Anáfora) e há os que remetem a elementos que serão mencionados no texto (fenômeno chamado Catáfora). Há outro grupo de mecanismos que marcam as relações de sentido entre as partes do texto, como as relações de oposição, finalidade, consequência, localização temporal, explicação, justificativa, adição de ideias (KOCH, 2018, p. 15). Todos esses elementos são importantes para formarem o tecido do texto como um todo por ligarem as partes e relacionarem os elementos, permitindo que se estabeleça uma relação de sentido.

Segundo Antunes (2005), a coesão cria, estabelece e sinaliza os laços capazes de ligar, articular e encadear os vários segmentos do texto. Ela dá ao texto a unidade de sentido ou unidade temática, ou seja, "daí que a função da coesão é exatamente a de promover a continuidade do texto, a sequência interligada de suas partes, para que não se perca o fio da unidade que garante a sua interpretabilidade" (ANTUNES, 2005, p. 48).

Para Antunes (2005), a continuidade semântica no texto se expressa por três tipos de relações: de reiteração, associação e conexão. Essas relações acontecem por meio de procedimentos que se desdobram em recursos diferentes. A coesão pela reiteração acontece quando os elementos do texto são retomados de forma que se liguem a palavras sem perder o fluxo do texto e sem deixar ideias soltas. Cada segmento do texto se liga a outro, tanto para trás quanto para frente. A coesão por associação acontece quando há ligação de sentido entre as palavras no texto. As relações se criam por meio de palavras de campo semântico semelhante ou afim, assegurando, assim, a unidade temática. Já a coesão por conexão acontece entre as orações, períodos, parágrafos ou blocos maiores por meio do uso de conectores (conjunções, preposições e locuções conjuntivas ou prepositivas).

Segundo Fávero (2004), a coesão acontece por meio da coesão referencial, recorrencial e sequencial. Obtém-se a coesão referencial por meio da substituição e reiteração. A substituição ocorre pela retomada por uma pró-forma (elemento gramatical que representa um nome, podendo ser formas pronominais, adverbiais, numerais). Quando há re- 
tomada, tem-se a anáfora, no caso de uma sucessão, tem-se a catáfora (FÁVERO, 2004, p. 18). Vale lembrar que somente os pronomes pessoais de terceira pessoa são pró-formas e que as pró-formas verbais se limitam aos verbos ser e fazer. Também pode ocorrer a substituição por zero (elipse).

A reiteração ocorre com a repetição de expressões, podendo ser por meio de repetição do mesmo item lexical, uso de sinônimos, uso de hiperônimos e hipônimos, uso de expressões nominais definidas e uso de nomes genéricos.

O segundo tipo de coesão, a recorrencial, ocorre com a progressão do texto, já que o fluxo de informações caminha, leva o discurso adiante, articula a informação nova à velha. A coesão recorrencial se dá por recorrência de termos, paralelismo (= recorrência de estruturas), paráfrase (= recorrência semântica), recursos fonológicos segmentais e supra-segmentais (FÁVERO, 2004, p. 26). A autora distingue recorrência de reiteração, pois a recorrência assinala que a informação progride, ao passo que a reiteração assinala que a informação já é conhecida e mantida.

Por fim, a coesão sequencial se dá por mecanismos que fazem progredir o texto e fluir as informações, diferenciando-se da coesão recorrencial por não retomar itens, sentenças ou estruturas. A coesão sequencial pode ocorrer por sequenciação temporal e por conexão (FÁVERO, 2004, p. 34).

Já Koch (2018), com base nos estudos de Halliday e Hasan (1976), destaca que há duas formas de coesão: a gramatical e a lexical. Koch (2018) postula a existência de duas modalidades de coesão: a coesão referencial (também chamada de coesão remissiva, de referenciação ou remissão) e a sequencial (sequenciação).

A coesão referencial acontece quando um "componente da superfície do texto faz remissão a outro(s) elemento(s) nela presentes ou inferíveis a partir do universo textual" (KOCH, 2018, p. 31). O elemento que faz remissão a outro é chamado de forma referencial ou remissiva e o elemento que é referido é chamado de elemento de referência ou referente textual.

A referência no texto pode ser feita por um nome, por um sintagma, por uma parte de uma oração, por uma oração inteira ou por todo um enunciado. Já o referente pode aparecer no texto como um sintagma nominal. À medida que o texto for se desenvolvendo esse referente pode 
ir sofrendo alterações na sua descrição, é o que se chama de (re)construção do referente, algo que acontece textualmente (KOCH, 2018, p. 31).

Há, conforme Koch (2018), duas formas referenciais: uma de ordem gramatical e outra de ordem lexical. As formas gramaticais são aquelas que não imprimem ao leitor/ouvinte relação de sentido, mas sim relação de conexão. Essas formas podem ser presas ou livres.

As formas remissivas gramaticais presas são todas aquelas que acompanham um nome (concordando em gênero e número), aparecendo antes dele ou antes do modificador que o acompanha dentro de um grupo nominal. Tais formas são representadas pelos artigos, pronomes adjetivos (demonstrativos, possessivos, indefinidos, interrogativos e relativos) e os numerais cardinais e ordinais, quando acompanharem nomes, visto que essas formas pertencem ao paradigma dos determinantes (KOCH, 2018, p. 34).

As formas remissivas gramaticais livres não são determinantes como as formas remissivas gramaticais presas e para o estabelecimento do sentido o contexto é extremamente importante. Elas são utilizadas para fazer a remissão seja por Anáfora ou Catáfora a até mais de um constituinte do texto. São representadas pelos pronomes pessoais de $3^{\mathrm{a}}$ pessoa e pelos pronomes substantivos de forma geral (demonstrativos, possessivos, etc.), pelas elipses, pelos numerais (quando não acompanham um nome, mas remetem a ele) e advérbios.

As formas remissivas lexicais são responsáveis pela conexão e referem-se a referentes extralinguísticos. São representadas pelos grupos nominais definidos (introduzidos por artigo definido ou demonstrativo), os sinônimos, hiperônimos, nomes genéricos, formas idênticas ou quase idênticas ao referente, etc.

No quadro a seguir, para melhor demonstração, temos a representação das formas referenciais: 
Quadro 1 - As formas referenciais de acordo com Koch (2018)

\begin{tabular}{|c|c|c|}
\hline \multicolumn{3}{|c|}{ Formas Referenciais } \\
\hline Gramaticais & - Presas & $\begin{array}{l}\text { - Artigos } \\
\text { - Pronomes adjetivos (demonstrativos, } \\
\text { possessivos, indefinidos, interrogativos, } \\
\text { relativos) } \\
\text { - Numerais cardinais e ordinais }\end{array}$ \\
\hline & - Livres & $\begin{array}{l}\text { - Pronomes pessoais de } 3^{\mathrm{a}} \text { pessoa } \\
\text { - Pronomes substantivos em geral } \\
\text { - Elipse } \\
\text { - Numerais } \\
\text { - Advérbios }\end{array}$ \\
\hline Lexicais & \multicolumn{2}{|c|}{$\begin{array}{l}\text { - Grupos nominais definidos } \\
\text { - Sinônimos } \\
\text { - Hiperônimos } \\
\text { - Nomes genéricos } \\
\text { - Formas idênticas ou quase idênticas ao referente }\end{array}$} \\
\hline
\end{tabular}

Fonte: Autora, com base em Koch (2018)

A seguir, apresentaremos algumas considerações acerca da coesão textual, mais especificamente, nos textos orais.

\section{A coesão textual nos textos orais}

Como já salientamos, Antunes (2005) destaca que a coesão textual pode ocorrer por meio de três relações: a de reiteração, a de associação e a de conexão. No recurso da reiteração, temos o procedimento da repetição e da substituição. Com relação à repetição, a autora apresenta que este não é um recurso exclusivo da fala, seja ela formal ou informal. Ademais, esse recurso é bastante significativo, visto que possibilita o reaparecimento de palavras já ocorridas no texto.

Segundo Antunes (2005), a repetição de palavras nos textos das duas modalidades da língua é um recurso textual bastante significativo por indicar ênfase a um determinado segmento. Ademais, "sua ocorrência 
em textos é incontestável, isto é, os textos maiores, orais ou escritos, formais ou informais, normalmente, trazem palavras repetidas, sem que isso lhes afete a qualidade" (ANTUNES, 2005, p. 71).

Com relação à repetição, ela é característica marcante do texto oral também para Fávero, Andrade e Aquino (2007) e importante no encadeamento das ideias. Para as autoras, "a alta incidência de repetições no texto falado é perceptível com facilidade e favorece a coesão, além de contribuir para a organização tópica" (FÁVERO, ANDRADE E AQUINO, 2007, p. 32). Além disso, a repetição é explicada como recurso utilizado pelo locutor para continuar com o turno, buscar uma melhor expressão ou para enfatizar uma ideia.

Após tais considerações acerca do aporte teórico que embasou nossa pesquisa, passaremos para o capítulo seguinte que trata da metodologia utilizada para a realização das oficinas de produção textual nas aulas de Língua Portuguesa na Escola Básica.

\section{Metodologia}

Esse artigo de cunho descritivo-analítico de base quanti-qualitativa visa apresentar uma análise da coesão referencial, de acordo com os estudos de Koch (2018), em dois textos, um escrito e um oral, de um aluno da Escola Básica. Esses textos foram coletados em oficinas de produção textual. As oficinas fazem parte de minha pesquisa de mestrado. A pesquisa ocorreu no ano de 2018, entre agosto e dezembro, em uma turma de sexto ano do Ensino Fundamental de uma Escola Básica da cidade de Santa Maria - RS. A turma era composta de 26 alunos, entre 11 e 14 anos, que ao longo das oficinas realizaram diversas atividades, como leitura e escuta de textos, interpretação textual, estudo de caraterísticas estruturais dos textos trabalhados, estudo básico da coesão textual, estudo dos elementos da narrativa e da estrutura da narrativa, e atividades de produção textual escrita e oral.

A pesquisa utilizou a metodologia da pesquisa-ação, proposta por Thiollent (2011) e Tripp (2005). Um dos objetivos da pesquisa-ação é "dar aos pesquisadores e grupo de participantes os meios de se tornarem capazes de responder com maior eficiência aos problemas da situação em que vivem, em particular sob forma de diretrizes de ação transformadora" (THIOLLENT, 2011, p. 14). Assim, há uma busca por soluções de problemas reais detectados em um contexto específico.

Por meio dessa metodologia, há o planejamento, a implementação, a descrição e avaliação em torno de uma prática a fim de ao longo do 
processo haver qualificação da prática e também da investigação em si (TRIPP, 2005, p. 446). Aos pesquisadores cabe a função de observação e equacionamento dos problemas encontrados, acompanhamento e avaliação dos problemas e das resoluções (THIOLLENT, 2011, p. 22).

$\mathrm{Na}$ ação em sala de aula, na implementação das oficinas, constituição e realização da pesquisa, a prática reflexiva, apontada nos estudos de Perrenoud (2002), também foi de extrema importância. Essa forma de agir insere-se perfeitamente no ciclo da pesquisa-ação, pois sempre que uma ação, nas oficinas, não surtia os efeitos esperados, planejava-se novas estratégias de ação para poder chegar aos resultados mais positivos possíveis. É por isso que essa metodologia tem sido conhecida como metodologia da articulação do conhecer e do agir, pois o agir remete a uma transformação orientada ao contexto e junto ao agir há o fazer que transforma algo da situação inicial.

A utilização da metodologia da pesquisa-ação requer um ciclo de ações para se chegar aos resultados. Tripp (2005) apresenta-nos um esquema do ciclo da investigação-ação:

Figura 1: Ciclo básico da investigação-ação

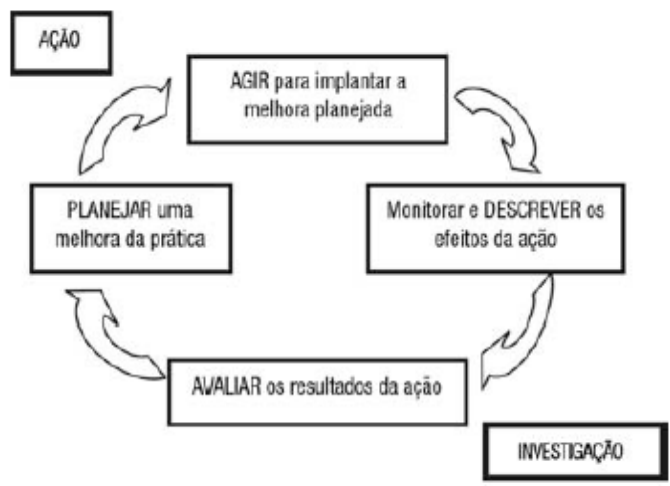

Fonte: (TRIPP, 2005, p. 446). 
Por meio desse esquema podemos depreender que em primeiro lugar, há a identificação do problema, depois segue-se para o planejamento da solução, há a implementação da solução, o monitoramento da implementação e a avaliação da eficácia da solução implementada. Se ocorrerem resultados inesperados ou diferentes dos planejados, reinicia-se o ciclo até que os problemas sejam resolvidos.

\section{Análise do corpus}

Analisaremos um texto escrito (TE) e um oral (TO) do mesmo aluno (chamaremos de "Aa"). O critério de seleção desse aluno foi a assiduidade nas oficinas. Os textos analisados são da produção textual escrita e oral realizada com base em um vídeo assistido pelos alunos na oficina. Atentaremos às ocorrências das Formas Referenciais Gramaticais Presas e Livres e Formas Referenciais Lexicais, de acordo com Koch (2018), destacando os elementos linguísticos responsáveis por realizar esse tipo de coesão.

Vejamos o Texto Escrito 1 (TE1) abaixo, conforme a imagem.

Imagem 1: Texto Escrito 1 (TE1) do Aluno "a" (Aa)

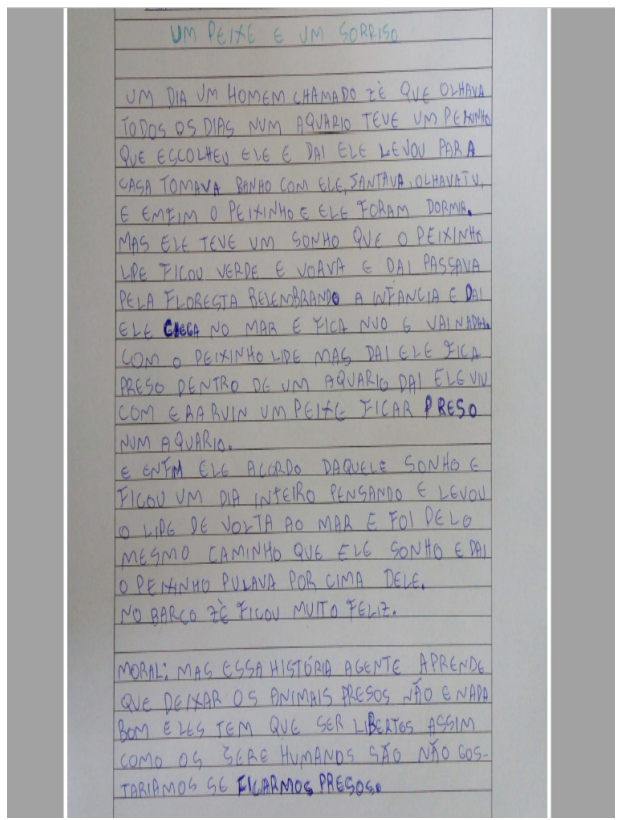

Fonte: aluno "a" 
No TE1 de Aa, o referente "um homem" é retomado por pronomes (pronome relativo "que", "ele"), contração de preposição com pronome ("dele"), elipses (nos verbos "teve", "tomava", "sentava", "olhava", "passava", “fica", "vai", “ficou”, "levou”, “foi”) e pelo nome próprio "Zé". Assim, Aa utilizou as Formas Referenciais Gramaticais Livres ao empregar os pronomes substantivos (pronomes pessoais de terceira pessoa - "ele" e "dele") e as elipses nos verbos já assinalados. Já ao utilizar os pronomes adjetivos (pronome relativo "que"), Aa apropriou-se das Formas referenciais Gramaticais Presas.

O referente "um peixinho" é retomado por pronomes ("que", "ele"), por elipse (no verbo "voava") e por expressões "o peixinho", "o peixinho Lipe" e "O Lipe". Dessa maneira, foram utilizadas as Formas Referenciais Gramaticais Livres ao empregar pronome substantivo (pronome pessoal de terceira pessoa "ele"), pronome adjetivo (pronome relativo "que") e as Formas Referenciais Lexicais ao empregar as formas nominais definidas em que um nome, geralmente um substantivo, é acompanhado por um determinante, como artigo, pronome, adjetivo ("o peixinho", "o peixinho Lipe", "O Lipe").

O quadro abaixo sinaliza as ocorrências das formas referenciais utilizadas por Aa em TE1: 
Quadro 2 - As ocorrências das Formas referenciais em TE1

\begin{tabular}{|c|c|c|c|c|}
\hline Referente & $\begin{array}{l}\text { Elementos } \\
\text { referenciais }\end{array}$ & Classe de palavras & Forma Referencial & $\begin{array}{l}\text { Número } \\
\text { de ocor- } \\
\text { rências }\end{array}$ \\
\hline \multirow{5}{*}{$\begin{array}{l}\text { Um ho- } \\
\text { mem }\end{array}$} & Que & Pronome relativo & Gramatical Presa & 1 \\
\hline & Elipse & $\begin{array}{l}\text { nos verbos Teve, } \\
\text { Tomava, Sentava, } \\
\text { Olhava, passava, } \\
\text { Fica, Vai, Ficou, } \\
\text { Levou, Foi }\end{array}$ & Gramatical Livre & 10 \\
\hline & Ele & $\begin{array}{l}\text { Pronome pessoal de } \\
3^{\mathrm{a}} \text { pessoa }\end{array}$ & Gramatical Livre & 9 \\
\hline & Dele & $\begin{array}{l}\text { Contração de Pre- } \\
\text { posição }+ \text { pronome } \\
\text { pessoal de } 3^{a} \text { pes- } \\
\text { soa }\end{array}$ & Gramatical Livre & 1 \\
\hline & Zé & Nome definido & Lexical & 1 \\
\hline \multirow{6}{*}{$\begin{array}{l}\text { Um pei- } \\
\text { xinho }\end{array}$} & Que & Pronome relativo & Gramatical Presa & 1 \\
\hline & Ele & $\begin{array}{l}\text { Pronome pessoal de } \\
3^{\mathrm{a}} \text { pessoa }\end{array}$ & Gramatical Livre & 1 \\
\hline & Elipse & $\begin{array}{l}\text { nos verbos voava, } \\
\text { passava }\end{array}$ & Gramatical Livre & 2 \\
\hline & O peixinho & $\begin{array}{l}\text { Expressão nominal } \\
\text { definida }\end{array}$ & Lexical & 3 \\
\hline & $\begin{array}{l}\text { O peixinho } \\
\text { Lipe }\end{array}$ & $\begin{array}{l}\text { Expressão nominal } \\
\text { definida }\end{array}$ & Lexical & 2 \\
\hline & O Lipe & $\begin{array}{l}\text { Expressão nominal } \\
\text { definida }\end{array}$ & Lexical & 1 \\
\hline
\end{tabular}

Fonte: Autora

Com isso, percebemos que, nesse texto, Aa utilizou, com maior frequência como estratégia de referenciação, os elementos linguísticos representados por pronomes de $3^{\mathrm{a}}$ pessoa e a elipse. Isso ocorreu, provavelmente, porque esse aluno não domina ainda as demais estratégias de utilização de elementos coesivos. A tendência foi a de simplificar a forma 
referencial, ao invés de utilizar, como por exemplo, expressões maiores que caracterizassem os referentes.

Passaremos para a análise do texto oral (TO) do aluno "a" (Aa), conforme a transcrição ${ }^{1}$ a seguir.

Texto oral 1: produção inicial de um texto oral a partir do vídeo "Um peixe, um sorriso"

A:: história começa assim...ele ficava todos os dias olhando o aquÁrio...daí até que um dia (risos) (o peixinho) riu dele...daí ele levou o peixinho pra casa...e ele fazia tudo com o peixinho...olhava televisão tomava banho...comia com o peixinho...tomava café com o peixinho...daí:: um dia ele foi dormir e sonhou que o peixinho era verde...daí o peixinho foi pro rio... e ele foi nadar junto com o peixinho e ficou dentro do acário...do aquÁrio... daí ele acordou...daí ele começou a pensar:: daí ele levou o peixinho e fugiu.

Fonte: Aluno "a"

Consideramos também para a análise do texto oral os estudos de Koch (2018). Dessa forma, temos em TO1 as seguintes ocorrências de referenciais: no início do texto aparece como primeiro referente o pronome pessoal de $3^{a}$ pessoa "ele" sem nenhuma outra caracterização. Há a retomada desse referente pelo pronome pessoal "ele", novamente, e por "dele" (contração de preposição e pronome pessoal). Outro recurso utilizado foi a elipse observada pelos usos dos verbos "olhava", "tomava", "comia", "sonhou", "ficou" e "fugiu". Para o segundo referente, "o peixinho", foi utilizada apenas a expressão igual "o peixinho" para fazer as retomadas.

Com isso, identificamos que, em TO1, foram utilizadas as Formas Referenciais Gramaticais Livres, evidenciadas pelo emprego de elipse e pronomes substantivos (pronomes pessoais de $3^{\text {a }}$ pessoa), e a Forma referencial Lexical evidenciada pelo uso de formas idênticas ("o peixinho").

O quadro abaixo sinaliza as ocorrências das formas referenciais utilizadas por Aa em TO1:

1 A transcrição dos textos narrativos orais foi realizada seguindo as normas estabelecidas pelo Projeto NURC/SP publicadas por Castilho e Preti (1987) 
Quadro 3 - As ocorrências de Formas Referenciais em T01

\begin{tabular}{|c|c|c|c|c|}
\hline Referente & $\begin{array}{l}\text { Elementos } \\
\text { referenciais }\end{array}$ & Classe de palavras & Forma Referencial & $\begin{array}{l}\text { Núme- } \\
\text { ro de } \\
\text { o c o r - } \\
\text { rências }\end{array}$ \\
\hline \multirow[t]{3}{*}{ Ele } & Ele & $\begin{array}{l}\text { Pronome pessoal } \\
\text { de } 3^{\mathrm{a}} \text { pessoa }\end{array}$ & Gramatical Livre & 7 \\
\hline & Dele & $\begin{array}{l}\text { Pronome pessoal } \\
\text { de } 3^{\mathrm{a}} \text { pessoa - con- } \\
\text { tração com prepo- } \\
\text { sição }\end{array}$ & Gramatical Livre & 1 \\
\hline & Elipse & $\begin{array}{l}\text { Nos verbos olha- } \\
\text { va, tomava, comia, } \\
\text { tomava, sonhou, } \\
\text { ficou, fugiu }\end{array}$ & Gramatical Livre & 7 \\
\hline $\begin{array}{l}\text { O peixi- } \\
\text { nho }\end{array}$ & O peixinho & $\begin{array}{l}\text { Forma idêntica ao } \\
\text { referente }\end{array}$ & Lexical & 8 \\
\hline
\end{tabular}

Fonte: Autora

Percebemos que em TO1 foi utilizada apenas a Forma Referencial Gramatical Livre para retomar o primeiro referente. Já para o segundo referente, foi utilizada apenas a Forma Referencial Lexical pelo uso de expressão idêntica. Além disso, a presença da repetição é bem marcante ao longo do texto oral, característica comum nos textos dessa modalidade da língua segundo Antunes (2005).

A história possui trechos não muito claros, pois um ouvinte que não assistiu ao vídeo dificilmente compreenderia os acontecimentos narrados. Porém destacamos que, no momento das oficinas, pelo fato de todos os alunos terem assistido ao vídeo, a história seria entendível. É provável que a falta de clareza (pensando na proposta da professora que era a de recontar a história do vídeo para um interlocutor que não assistiu) seja uma consequência da timidez, pois o aluno, na situação da sala de aula, encontrava-se bastante inseguro com relação à produção de texto oral, devido à falta de atividades como essa em sala de aula.

No texto escrito, do total de trinta e duas retomadas de referentes, o aluno utilizou as Formas Referenciais Gramaticais Presas em apenas duas ocorrências por meio do pronome relativo "que". Já as Formas Referen- 
ciais Gramaticais Livres foram utilizadas em vinte e três ocorrências por meio de pronome pessoal de $3^{a}$ pessoa e de elipses. Já as Formas Referenciais Lexicais foram usadas em sete ocorrências por meio das expressões nominais definidas.

No texto oral, do total das vinte e três retomadas de referentes, o aluno utilizou as Formas Referenciais Gramaticais Livres em quinze ocorrências por meio de pronome pessoal de $3^{\text {a }}$ pessoa e elipses. Já as Formas Referenciais Lexicais foram usadas em oito ocorrências apenas por meio de retomada por forma idêntica ao referente.

O quadro a seguir sinaliza as ocorrências nos dois textos:

Quadro 4 - As ocorrências das Formas Referenciais no texto escrito e oral

\begin{tabular}{|l|l|l|l|}
\hline & $\begin{array}{l}\text { Te x to } \\
\text { escrito }\end{array}$ & Texto oral & Recursos linguísticos \\
\hline $\begin{array}{l}\text { Ocorrências de For- } \\
\text { mas Referenciais } \\
\text { Gramaticais Presas }\end{array}$ & 2 & 0 & Pronome relativo "que" \\
\hline $\begin{array}{l}\text { Ocorrências de For- } \\
\text { mas Referenciais } \\
\text { Gramaticais Livres }\end{array}$ & 23 & 15 & $\begin{array}{l}\text { Pronome pessoal de 3a pessoa e } \\
\text { elipse }\end{array}$ \\
\hline $\begin{array}{l}\text { Ocorrências de For- } \\
\text { mas Referenciais } \\
\text { Lexicais }\end{array}$ & 7 & 8 & $\begin{array}{l}\text { expressões nominais definidas } \\
\text { (no texto escrito) e forma idên- } \\
\text { tica ao referente (no texto oral) }\end{array}$ \\
\hline $\begin{array}{l}\text { Total de ocorrências } \\
\text { de referenciação }\end{array}$ & 32 reto- \\
madas & $\begin{array}{l}23 \text { retoma- } \\
\text { das }\end{array}$ & \\
\hline
\end{tabular}

Fonte: Autora

Tanto TE1 quanto TO1 apresentam as Formas Referenciais Gramaticais Livres como dominantes para realizar a referenciação de referentes. A diferença entre os dois textos é que no texto oral nenhuma Forma Referencial Gramatical Presa foi utilizada. Provavelmente, isso ocorreu pelo fato de o texto escrito ser mais extenso, além, é claro, da característica do texto oral de ser mais espontâneo. Mesmo que os dois textos sejam narrativas da história contada no mesmo vídeo, o texto escrito é mais extenso e possui maior número de ocorrências de referenciação por meio 
das Formas Referenciais destacadas por Koch (2018), sendo trinta e duas ocorrências no texto escrito e vinte e três no texto oral. Isso pode ser reflexo do tempo de planejamento que é diferente nos dois textos.

A repetição de Formas Referenciais utilizada pelo aluno na produção do texto escrito e oral justifica-se, conforme Antunes (2005) aponta, pois a repetição é um recurso utilizado não somente na fala informal ou formal para encadear as ideias, mas também para propiciar o reaparecimento de palavras que já foram mencionadas no texto, seja ele oral ou escrito. Assim, tanto em TE1 como em TO1 há maior utilização das Formas Referenciais Gramaticais Livres representadas pelos pronomes de $3^{\text {a }}$ pessoa e elipses que aparecem no texto repetidamente com uma finalidade importante: a de encadear as deias e fazer reaparecer uma palavra já mencionada.

Conforme salientamos, diante da oportunidade de produzir uma narrativa escrita, Aa teve mais tempo para pensar e escrever o que planejou. Na situação de produção de texto oral, o aluno precisou produzir sua narrativa no momento em que estava diante do público, ou seja, o tempo de planejamento é menor em relação ao texto escrito. Tal fator, possivelmente, influenciou no número das ocorrências das Formas Referenciais. Soma-se a isso que, a utilização de Formas Referenciais repetidas ao longo dos textos nas duas modalidades não se dá apenas pelo tempo de planejamento, mas também porque a repetição é um recurso estratégico comum para o reaparecimento de um objeto no texto. Também como afirmam Fávero, Andrade e Aquino (2007), as repetições no texto falado são notadas com facilidade e possuem o papel de favorecer e auxiliar na coesão textual. Isso ocorre porque do mesmo modo que mantém vivo um referente ao longo de todo o texto também auxilia na progressão do texto. Cabe lembrar que recurso da repetição não é exclusivo da fala. E isso se comprova na análise do texto escrito.

\section{Considerações finais}

Percebemos que os mecanismos linguísticos utilizados com maior frequência nos textos escritos foram o pronome pessoal de $3^{a}$ pessoa e as elipses. No texto oral, ocorreu do mesmo modo. Em segundo lugar, ocorre com mais frequência o uso das Formas Referenciais Lexicais pelo uso de expressões nominais definidas ou expressões idênticas ao referente. $\mathrm{O}$ uso das Formas Referenciais Gramaticais Livres se sobressai às demais formas. Com menor ocorrência, no texto escrito, aparece a Forma Refe- 
rencial Gramatical Presa. No texto oral, a Forma Referencial Gramatical Presa não aparece. As Formas Referenciais aparecem de modo repetido com bastante frequência, conforme foi observado na análise.

A ocorrência de repetições não sinaliza um "erro" propriamente dito, já que, conforme Antunes (2005), a repetição é uma estratégia que mantém vivo no texto um objeto já mencionado. Tal recurso não é exclusivo da fala, pois pode aparecer nos textos escritos como forma de manter um referente ao longo do texto. A repetição também favorece a coesão textual, conforme salientam Fávero, Andrade e Aquino (2007), pois possibilita a manutenção do referente ao longo do texto, além de propiciar a progressão textual.

A partir da análise realizada nesse artigo, reforçamos o que os PCNs apontam com relação à importância de atividades que explorem não só a produção de textos escritos, mas também de textos orais. Além disso, destacamos a relevância de explorar as potencialidades dos alunos com relação à referenciação de referentes nos textos.

Por mais que as repetições nos usos de Formas Referenciais não caracterizem um "erro", já que a repetição é uma estratégia de manter o referente vivo no texto, de reaparecimento de um objeto por meio de palavras, no cotidiano da sala de aula, certamente, será possível perceber que os alunos possuem muitas outras habilidades a serem exploradas no que diz respeito à manutenção do referente no texto. A habilidade de referenciar de formas variadas, não apenas pela utilização do recurso da repetição, pode e deve ser explorada e, certamente, há maneiras de utilização de estratégias diversas à disposição na língua.

Atividades que envolvam a utilização de sinônimos, de expressões nominais definidas, de expressões que auxiliam na caracterização de personagens, na descrição de espaços, a utilização de hiperônimos e hipônimos, as nominalizações, são formas linguísticas que podem ser utilizadas nos textos escritos e orais pelos alunos. O manuseio de dicionários pode auxiliar os alunos na produção textual e pode possibilitar usos mais diversificados de Formas Referenciais. Além disso, outra estratégia seria a produção textual coletiva ou mais interativa entre colegas para que outras maneiras de referir a objetos no texto possam ser pensadas e utilizadas. 


\section{REFERÊNCIAS BIBLIOGRÁFICAS}

ANTUNES, I. Lutar com palavras: coesão e coerência. São Paulo: Parábola Editorial, 2005.

BEAUGRANDE, R; DRESSLER, W. U. Introduction to text linguistics. London/ New York: Longmam, 1981.

BRASIL. Secretaria de Educação Fundamental. Parâmetros curriculares nacionais: língua portuguesa / Secretaria de Educação Fundamental. - Brasília: 1997. FÁVERO, L. L. Coesão e coerência textuais. São Paulo: Ática, 2004.

CASTILHO, A. T; PRETI, D. A linguagem falada culta na cidade de São Paulo: materiais para seu estudo. São Paulo: T. A. Queiroz, FAPESP, 1987.

FÁVERO, L. L; ANDRADE, M. L. C. V. O; AQUINO, Z. G. O. Oralidade e escrita: perspectiva para o ensino de língua materna. 6. Ed. São Paulo: Cortez, 2007.

HALliDAY, M. A. K; HASAN, R. Cohesoion in English. London: Longmam, 1976.

KOCH, I. G. V; TRAVAGLIA, L. C. Texto e coerência. São Paulo: Cortez, 2003.

KOCH, I. G. V. Introdução à Linguística Textual: trajetórias e grandes temas. São Paulo: Contexto, 2017. . A coesão textual. 22. Ed. São Paulo: Contexto, 2018.

PERRENOUD, P. A prática reflexiva no ofício do professor: profissionalização e razão pedagógicas. Porto Alegre: Artmed Editora, 2002.

THIOLlENT, M. Metodologia da pesquisa-ação. São Paulo: Cortez, 2011.

TRIPP, D. Pesquisa-ação: uma introdução metodológica. In: Educação e Pesquisa. v. 31, n. 3. São Paulo, 2005. Educação e Pesquisa, São Paulo, v. 31, n. 3, p. 443-466, set./dez. 2005.

Recebido em: 24/07/2019

Aceito em: 05/01/2020 